makes the wound sterile in lesser time, has a better outcome in terms of prevention of hypertrophic scarring and postburn contractures, and decreases the need of debridement irrespective of time of admission, when compared to SSD dressing" ${ }^{[1]}$ Indeed, several reports confirm the possibility of using honey dressing for burn patients. ${ }^{[2,3]}$ However, according to the meta-analysis, it is shown that "Honey dressings as an adjuvant to compression do not significantly increase leg ulcer healing at 12 weeks. There is insufficient evidence to guide clinical practice in other areas". ${ }^{[3]}$ The main flaw of the report by Baghel et al. is the lack of a matched control group in the study ${ }^{[1]}$ In addition, an important problem to be concerned is the sterility of the honey. The contamination of Clostridium should not be overlooked. ${ }^{[4]}$

Viroj Wiwanitkit

Wiwanitkit House, Bangkhae, Bangkok, Thailand

Address for correspondence: Viroj Wiwanitkit, Wiwanitkit House, Bangkhae, Bangkok, Thailand - 10160 . E-mail:wviroj@yahoo.com

\title{
REFERENCES
}

DOI: 10.4103/0970-0358.63947

1. Baghel PS, Shukla S, Mathur RK, Randa R. A comparative study to evaluate the effect of honey dressing and silver sulfadiazene dressing on wound healing in burn patients. Indian J Plast Surg 2009;42:176-81.

2. Wijesinghe $M$, Weatherall $M$, Perrin K, Beasley R. Honey in the treatment of burns: A systematic review and meta-analysis of its efficacy. N Z Med J 2009;122:47-60.

3. Jull $A B$, Rodgers $A$, Walker N. Honey as a topical treatment for wounds. Cochrane Database Syst Rev 2008;8:CD005083.

4. Bogdanov S, Jurendic T, Sieber R, Gallmann P. Honey for nutrition and health: A review. J Am Coll Nutr 2008;27:677-89.

\section{Honey vs. silver sulphadiazine}

Sir,

I read the recent publication by Baghel et al. on wound healing in burn patients with great interest..1] Bahgel et al. concluded that "Honey dressing improves wound healing, 